\title{
Variations in the distribution of sugar residues in the zona pellucida as possible species-specific determinants of mammalian oocytes
}

\author{
E. Skutelsky ${ }^{1}$, E. Ranen ${ }^{3}$ and R. Shalgi ${ }^{2}$ \\ Departments of ${ }^{1}$ Pathology and ${ }^{2}$ Embryology, Sackler Faculty of Medicine, Tel Aviv University, \\ Ramat Aviv, Israel; and ${ }^{3}$ Koret School of Veterinary Medicine, The Hebrew University of \\ Jerusalem, Rehovot, Israel
}

\begin{abstract}
The lectin-binding patterns of mammalian zonae pellucidae were investigated to determine whether differences reflected their characteristic carbohydrate distribution patterns. Ovaries isolated from rodents (mouse, rat and hamster), rabbits, cats, dogs and pigs were fixed with glutaraldehyde and embedded in paraffin wax. Sections $5 \mu \mathrm{m}$, were deparaffinized, rehydrated and labelled with ten different biotinylated lectins as probes and avidin-biotinperoxidase complex as visualant. The zonae pellucidae of all animals studied exhibited species-specific variations in lectin-binding patterns, whereas the lectin binding of their granulosa cells and follicular fluids were identical. Phylogenetically close species, such as the rodents and rabbits demonstrated high similarity in zona pellucida saccharides, expressed in binding of succinylated wheatgerm agglutinin and peanut agglutinin. Lectins such as Dolichos biflorus agglutinin, which binds only to mouse, Griffonia simplicifolia (GS-I), which binds to mouse and rat but not hamster and rabbit and soybean agglutinin, which binds only to rodents, reflect characteristic differences between phylogenetically related mammals.
\end{abstract}

\section{Introduction}

The zona pellucida is an extracellular elastic coat that surrounds the vitelline membrane of mammalian oocytes (Wassarman, 1988). The zona pellucida has several important functions in fertilization, including serving as a sperm receptor, inducing the acrosome reaction and preventing penetration of more than one spermatozoon (Yanagimachi, 1988). Biochemical analysis of the zona pellucida in some mammalian species, such as humans (Shabanovitz and O'Rand, 1988), mice (Wassarman, 1988), hamsters (Moller et al., 1990) and pigs (Dunbar and Raynor, 1980), revealed that it contains only a few glycoproteins, which vary in molecular mass and electrical charge, depending on species.

Most of the studies on the zona pellucida were performed in mice. The mouse zona pellucida consists of three glycoproteins - ZP1, ZP2 and ZP3 - which differ in their polypeptide chains and oligosaccharides (Wassarman, 1988). The sugar residues characterizing oligosaccharide chains of the $\mathrm{ZP}$ glycopeptides play a major role in the binding of spermatozoa to the zona pellucida (Macek and Shur, 1988; Miller and Ax, 1990). In mice, the O-linked oligosaccharides of ZP3 were reported to serve as receptor sites for the spermatozoa (Florman and Wassarman, 1985; Bleil and Wassarman, 1988). Bleil and Wassarman (1988) demonstrated that $\alpha$-galactosyl residues of the mouse zona pellucida function as sperm receptors, whereas in rats the sugars participating in sperm binding are L-fucose, D-mannose and methyl-mannoside (Shalgi et al., 1986), L-fucose and D-galactose are probably

Received 21 January 1993 involved in this process in hamsters, guinea-pigs and humans (Huang et al., 1982).

Previous studies have used lectins as sugar-specific histochemical markers to investigate sugar distribution in mammalian cells and tissues (Alroy et al., 1984; Spicer and Schulte, 1992). Lectins are sugar-binding proteins or glycoproteins of non-immune origin which agglutinate cells or precipitate glycoconjugates having saccharides of appropriate complementarity (Goldstein et al., 1980). They were previously used to characterize the zona pellucida of mice, rats and hamsters by light and electron microscopy (Nicolson et al., 1975; Shimizu et al., 1982; Wu et al., 1984). Several studies have shown that lectins can block sperm binding to zonae pellucidae in various species, including humans (Oikawa ef al., 1973; Nicolson et al., 1975; Mori et al., 1989). Studies on the mouse ovary showed differences in the intensity of binding of various lectins to the zona pellucida, which reflect variations in the content or availability of different sugar residues (Wu et al., 1984).

The pattern of lectin binding to zonae pellucidae of rat oocytes was investigated by Shalgi ef al. (1991). We demonstrated that in follicular oocytes some lectin receptor sites tend to exhibit an uneven distribution throughout the zona pellucida.

The results so far suggest that specific sugar residues in the zona pellucida of the mammalian oocytes are probably the key for the species specificity of gamete interaction. Identification of characteristic sugar residues in the zona pellucida, their distribution and variations in their expression in different mammalian species is important in understanding the processes involved in gamete binding and penetration of the spermatozoon through the zona pellucida during fertilization. 
Table 1. Lectins used for identifying carbohydrate residues in follicular oocytes

\begin{tabular}{|c|c|c|c|c|c|}
\hline Lectin origin & Common name & Acronym & Concentration $\left(\mu \mathrm{g} \mathrm{ml}^{-1}\right)$ & Major sugar specification ${ }^{a}$ & Binding inhibitor \\
\hline Arachis hypogea & Peanut & PNA & 20 & Gal $\beta-(1-3)-G a l N A c$ & Lactose \\
\hline Griffonia simplicifolia & Griffonia & GS-I & 50 & $\alpha-\mathrm{D}-\mathrm{Gal}$ & Lactose \\
\hline Concanavalia ensiformis & Jack bean & Con A & 10 & $\alpha D-G L c, \alpha-D-M a n$ & $\alpha$-D-methyl-Man \\
\hline Dolichos biflorus & Horse gram & $\mathrm{DBA}$ & 10 & $\alpha-\mathrm{D}-\mathrm{GalNAc}$ & $\alpha$-D-GalNAc \\
\hline Glycine $\max$ & Soybean & SBA & 10 & $\alpha-\mathrm{D}-\mathrm{GalNAc}, \alpha-\mathrm{D}-\mathrm{Gal}$ & $\alpha-\mathrm{D}-\mathrm{GalNAc}$ \\
\hline Lens culinaris & Common lentil & LCA & 10 & $\alpha-\mathrm{D}-\mathrm{GLC}, \alpha$-D-Man & $\alpha$-D-methyl-Man \\
\hline Ricinus communis & Castor bean & RCA-I & 50 & $\beta$-D-Gal & Lactose \\
\hline Triticum vulgaris & Wheat germ & WGA & 50 & $\beta-(1-4)-(\mathrm{D}-\mathrm{GlcNAc})_{2} \mathrm{NeuNAc}$ & NeuNAc \\
\hline Triticum vulgaris & Succinyl-WGA & S-WGA & 10 & $\beta-(I-4)-(D-G l c N A c)_{2}$ & $\beta$-D-GlcNAc \\
\hline Ulex europaeus & Gorse & UEA-I & 10 & $\alpha$-L-fucose & $\alpha$-L-fucose \\
\hline
\end{tabular}

${ }^{2}$ Gal: galactose; GalNAc: $N$-acetylgalactosamine; GlcNAc: $N$-acetylglucosamine; NeuNAc: $N$-acetylneuraminic acid (sialic acid); Man: mannose.

The present study was undertaken to examine the possibility that the zona pellucida of follicular oocytes in different mammalian species exhibit differences in lectin-binding patterns. Such differences may reflect specific sugar distribution patterns of the zona pellucida that could serve as determinants in species-specific gamete interaction.

\section{Materials and Methods}

\section{Oocytes}

Rats (24-26-day-old) were induced to superovulate by an s.c. injection of 15 iu pregnant mares' serum gonadotrophin (PMSG: Intravent, The Netherlands). Twenty-four hours after PMSG treatment, the rats were killed by cervical dislocation and their ovaries were isolated. In one experiment, ovaries were removed from mature (4-month-old) rats without hormonal stimulation. Mouse and hamster ovaries were obtained in the same manner (5 iu PMSG for 3-month-old mice and 40 iu PMSG for 2-month-old hamsters, administered i.p.). Ovaries were obtained from 2 -month-old rabbits. Pig ovaries (5-6 months old) were obtained from an abattoir. Dog and cat ovaries were obtained from young females (7-18-months-old) undergoing sterilization.

All ovaries were fixed immediately in $2.5 \%$ glutaraldehyde in $0.2 \mathrm{~mol}$ phosphate buffer $1^{-1}, \mathrm{pH} \mathrm{7.4}$, and embedded in paraffin wax.

\section{Histochemical analyses}

The paraffin wax embedded tissue sections $(5 \mu \mathrm{m}$ thick) were deparaffinized by xylene and ethanol, and rehydrated with phosphate-buffered saline (PBS). Endogenous peroxidase was blocked by incubation in $2 \% \mathrm{H}_{2} \mathrm{O}_{2}$ at $37^{\circ} \mathrm{C}$ for $10 \mathrm{~min}$. The sections were covered with $1 \%$ BSA solution in PBS, for $10 \mathrm{~min}$; the excess solution was shaken off; and the slides around the tissue section were blotted. The sections were then incubated with one of ten different biotin-labelled lectins (Vector Laboratories, Burlingame, CA) for $60 \mathrm{~min}$, washed three times in PBS and incubated with avidin-biotin- peroxidase complex (Vector Laboratories) for $30 \mathrm{~min}$, followed by three washes with PBS. The visualant, horseradish peroxidase, was activated by incubation for 5-8 $\mathrm{min}$ in PBS solution containing diaminobenzidine and $\mathrm{H}_{2} \mathrm{O}_{2}$. The sections were then washed in tap water for $5 \mathrm{~min}$, counterstained with $0.2 \%$ aqueous solution of methyl green, dehydrated and covered with Merkoglass. For identification of cryptic peanut agglutinin (PNA) receptor sites, the deparaffinized tissue sections were first incubated for $1 \mathrm{~h}$ at $37^{\circ} \mathrm{C}$ with $1 \mathrm{U}$ neuraminidase $\mathrm{ml}^{-1}$ (from Clostridium perfringens: Sigma, St Louis, MO) in acetate

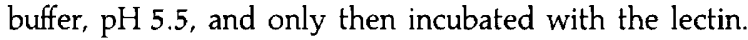

In rabbits, pigs, dogs and cats, the histochemical analyses were performed on at least five ovaries from five different animals. The analyses of rodent ovaries (mouse, rat and hamster) were performed on at least 10 different animals.

The lectins used in this study, the concentrations used, their major sugar specificities and the corresponding sugars used to inhibit their binding are listed (Table 1). The concentrations selected were shown to give minimal background, but were sufficient to detect relatively low amounts of specific sugar residues. Incubation of the lectins with the appropriate solutions of corresponding sugar haptens (Table 1), before and during the application of the lectin solution to the tissue section, served as specific controls. Incubation of the sections with avidin-biotin-peroxidase complex alone served as a nonspecific negative control.

The lectin-stained slides were examined microscopically and the staining defined as positive or negative. The degree of staining was described semiquantitatively as negative $(-)$, weakly positive $( \pm)$ or positive $(+)$.

\section{Results}

Analyses of lectin binding in follicular oocytes in the ovaries were designed to examine the distribution or availability of sugar residues in the zonae pellucidae of follicular oocytes. The lectin-binding patterns of the oocytes, granulosa cells and follicular fluid are also described.

There was little variation in the lectin-binding patterns of zonae pellucidae among animals of the same species (Table 2). On the contrary, lectin-binding patterns of the zonae pellucidae 
Table 2. Lectin-binding to ovaries of different mammalian species

\begin{tabular}{|c|c|c|c|c|c|c|c|c|}
\hline Lectin $^{a}$ & & Mouse & Rat & Hamster & Rabbit & Cat & Dog & Pig \\
\hline \multirow[t]{3}{*}{ Con A } & $\mathrm{ZP}$ & $\pm^{+}$ & $\pm^{+}$ & $\pm^{\dagger}$ & $\pm^{\dagger}$ & - & - & - \\
\hline & GR & + & + & + & + & + & + & + \\
\hline & $\mathrm{FF}$ & + & + & + & + & + & + & + \\
\hline \multirow[t]{3}{*}{ LCA } & $\mathrm{ZP}$ & \pm & \pm & \pm & $t^{\dagger}$ & - & \pm & \pm \\
\hline & GR & + & + & + & + & + & + & + \\
\hline & $\mathrm{FF}$ & + & + & + & + & + & + & + \\
\hline \multirow[t]{3}{*}{ WGA } & $\mathrm{ZP}$ & $+t i$ & + & $++^{\dagger \dagger}$ & + & - & + & + \\
\hline & GR & + & + & + & + & + & + & + \\
\hline & $\mathrm{FF}$ & + & + & + & + & + & + & + \\
\hline \multirow[t]{3}{*}{ S-WGA } & $\mathrm{ZP}$ & $+^{\dagger}$ & $+^{\dagger}$ & $t^{\dagger}$ & $+^{\dagger}$ & - & - & - \\
\hline & GR & - & - & - & - & - & - & - \\
\hline & $\mathrm{FF}$ & - & - & - & - & - & - & - \\
\hline \multirow[t]{3}{*}{ PNA } & $\mathrm{ZP}$ & + & + & $+^{+}$ & \pm & - & - & - \\
\hline & $\mathrm{GR}$ & - & - & - & - & - & - & - \\
\hline & $\mathrm{FF}$ & - & - & - & - & - & - & - \\
\hline \multirow[t]{3}{*}{ N-PNA* } & $\mathrm{ZP}$ & + & + & $+^{\dagger}$ & - & - & - & - \\
\hline & GR & + & + & + & + & + & + & + \\
\hline & $\mathrm{FF}$ & + & + & + & + & + & + & + \\
\hline \multirow[t]{3}{*}{ RCA-I } & $\mathrm{ZP}$ & $+^{\dagger}$ & $+^{+}$ & $+^{\dagger}$ & $+^{\dagger}$ & $+^{+}$ & - & $t^{+}$ \\
\hline & GR & + & + & + & + & + & + & + \\
\hline & $\mathrm{FF}$ & + & + & + & + & + & + & + \\
\hline \multirow[t]{3}{*}{ GS-I } & $\mathrm{ZP}$ & $+^{\dagger+\dagger}$ & + & - & - & - & - & - \\
\hline & GR & - & - & - & - & - & - & - \\
\hline & $\mathrm{FF}$ & - & - & - & - & - & - & - \\
\hline \multirow[t]{3}{*}{ SBA } & $\mathrm{ZP}$ & + & + & + & - & - & - & - \\
\hline & GR & - & - & - & - & - & - & - \\
\hline & $\mathrm{FF}$ & - & - & - & - & - & - & - \\
\hline \multirow[t]{3}{*}{ DBA } & $\mathrm{ZP}$ & $++^{\dagger+\dagger}$ & - & - & - & - & - & - \\
\hline & $\mathrm{GR}$ & - & - & - & - & - & - & - \\
\hline & $\mathrm{FF}$ & - & - & - & - & - & - & - \\
\hline \multirow[t]{3}{*}{ UEA-I } & $\mathrm{ZP}$ & - & - & - & - & - & - & - \\
\hline & $\mathrm{GR}$ & - & - & - & - & - & - & - \\
\hline & $\mathrm{FF}$ & - & - & - & - & - & - & - \\
\hline
\end{tabular}

${ }^{a}$ See Table $I$ for lectin name.

ZP: zona pellucida.

GR: granulosa cells.

FF: follicular fluid.

external zona pellucida.

${ }^{+\dagger}$ external and internal zona pellucida.

${ }^{\dagger+}$ internal zona pellucida.

*N-PNA: PNA used after neuraminidase treatment.

varied considerably among the species examined. The extent of variation was generally correlated with the evolutionary relationship among the species examined, exhibiting greater similarity between closely related species (for example mouse, rat and hamster), and more pronounced differences between distantly related species (i.e. murine versus canine, feline and porcine species). The lectin-binding patterns of granulosa cells and follicular fluids were similar in all species studied (Table 2). To rule out the possibility that the hormonal stimulation of the females affected the composition of the glycoproteins of the zonae pellucidae, we examined the lectin binding pattern of the zonae pellucidae of mature cyclic rats. No differences in 

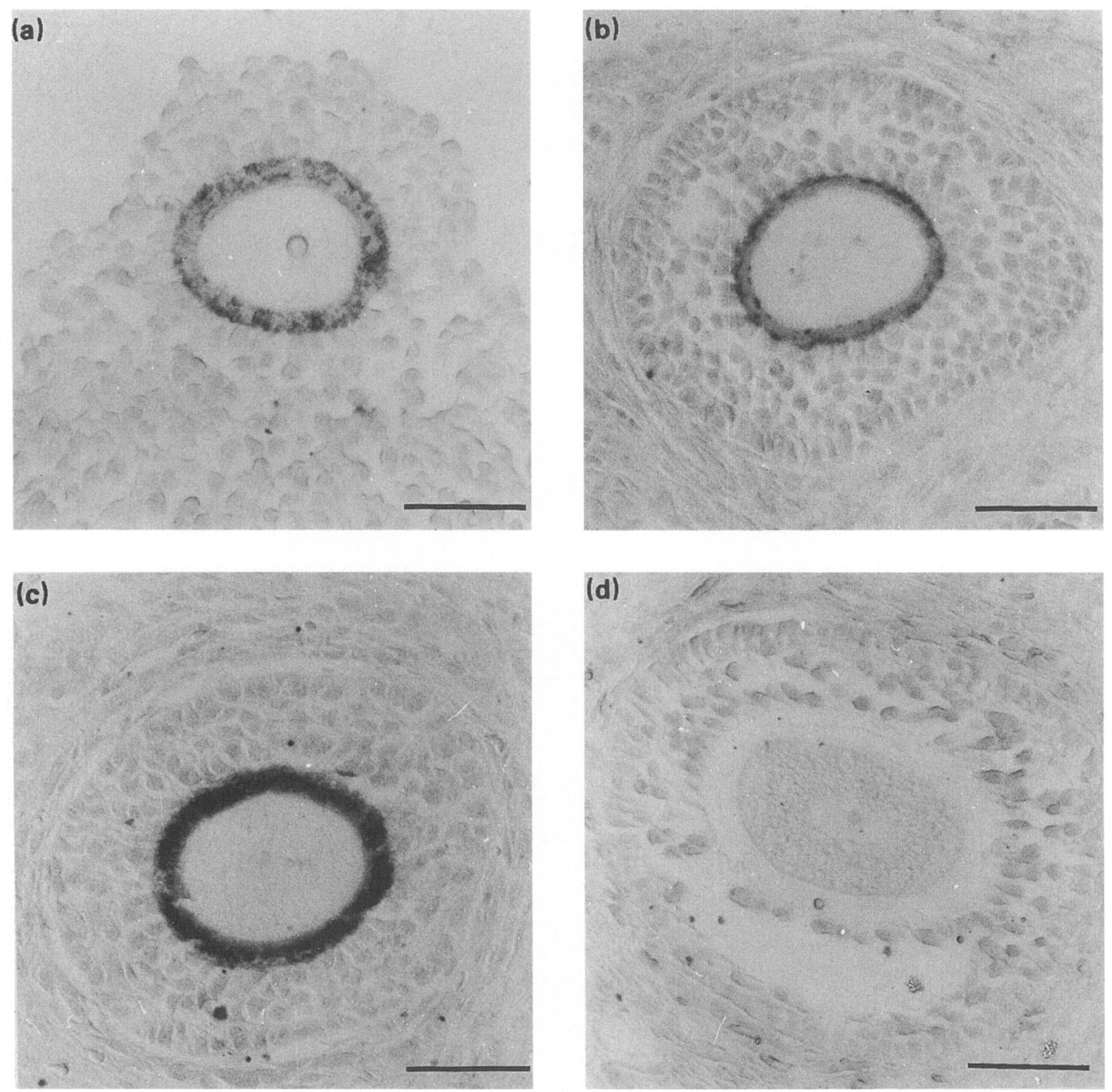

Fig. 1. Photomicrographs of deparaffinized sections of ovaries, labelled with biotinylated soybean agglutinin (SBA) visualized by avidin-biotin-peroxidase complex and counterstained with methyl green. The zona pellucida of (a) rat, (b) mouse and (c) hamster exhibits moderate to intense binding of the lectin, whereas the rabbit zona pellucida (d) is unlabelled. The oocyte itself and the granulosa cells surrounding it in all the ovaries are not labelled by the lectin. Bars represent $50 \mu \mathrm{m}$.

carbohydrate distribution were noticed in this group compared with the zonae pellucidae of the hormonally stimulated immature rats.

Some of the lectins used, for example wheat germ agglutinin (WGA), Ricinus communis agglutinin-I (RCA-I) and, to a lesser extent, Lens culinaris agglutinin (LCA) reacted positively with the zona pellucida of almost all species studied, although in different intensities. One lectin, Ulex europaeus agglutinin-I (UEA-I), did not bind to the zona pellucida of any of the species examined. The remaining lectins used stained the zona pellucida in only some species.

A pronounced similarity in lectin-binding patterns was seen among the rodents, for example mice, rats and hamsters, and to a lesser extent, rabbits (Table 2). Some of the lectins, including succinylated-WGA (S-WGA) and PNA bound to the zona pellucida of all rodents and of rabbits, but did not bind to the zona pellucida of other species studied. Among the former species, the differences in lectin binding were generally minor and were expressed in the binding of soybean agglutinin (SBA), Griffonia simplicifolia agglutinin-I (GS-I) and Dolichos biflorus agglutinin (DBA). SBA positively stained the zonae pellucidae of mice, rats and hamsters (Fig. Ia-c), but not of rabbits (Fig. Id); GS-I bound to the zonae pellucidae of rats and mice (Fig. 2a), but not to those of hamsters and rabbits; and DBA bound only to the zona pellucida of the mouse. These lectins did not bind at all in cats, dogs and pigs.

In most instances lectin receptors were unevenly distributed throughout the depth of the zonae pellucidae (Table 2). Thus, for example, the binding sites for RCA-I (Fig. 2b), S-WGA, Concanavalia ensiformis agglutinin (Con A) and PNA (Fig. 2c) were restricted mainly to the outer regions of the zona pellucida, whereas those for GS-I (Fig. 2a) and DBA in mice 

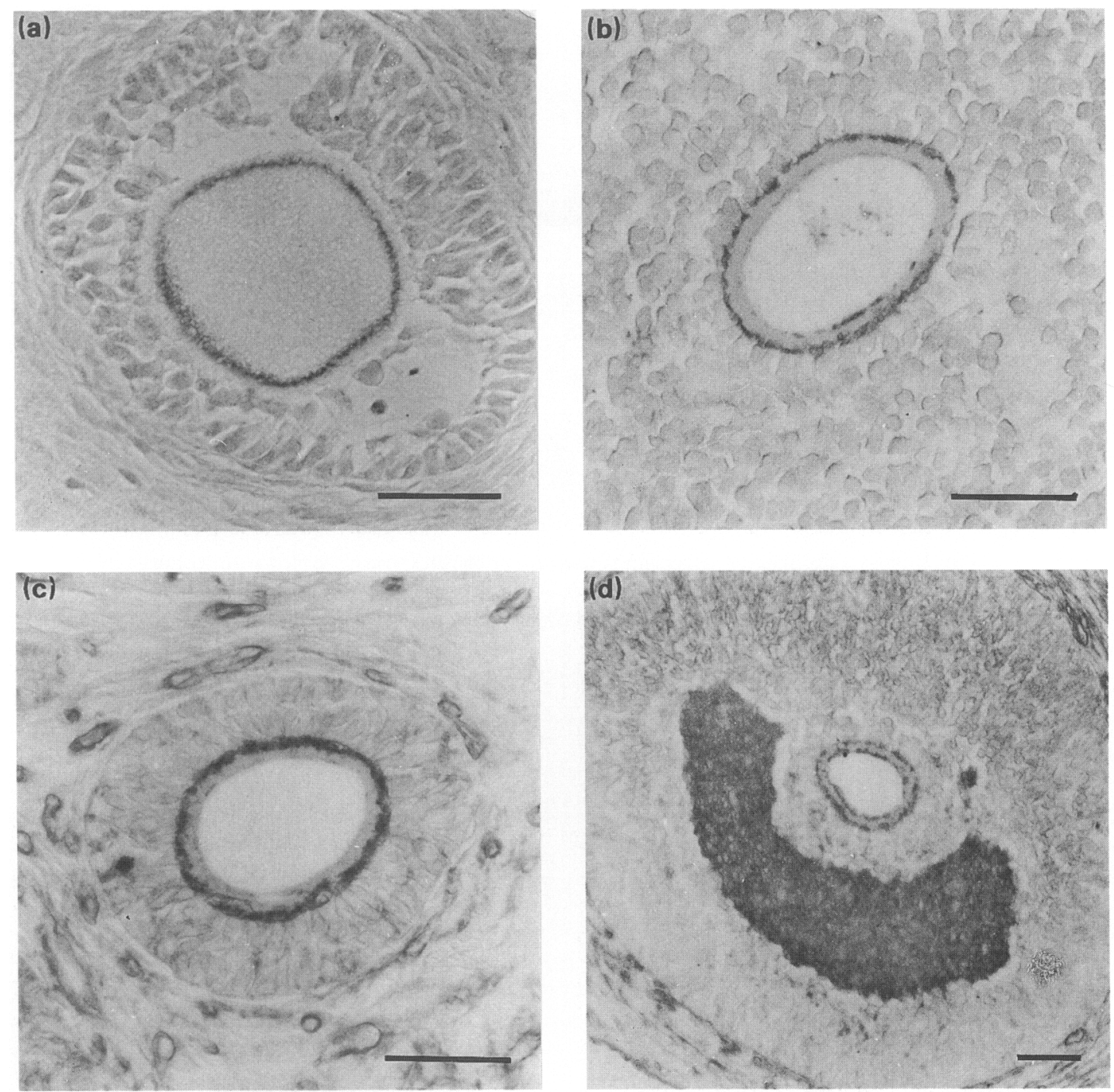

Fig. 2. Photomicrographs of deparaffinized sections of (a) mouse and (b-d) hamster ovaries, labelled with biotinylated (a) Griffonia simlisifolia lectin-I, (b) Ricinus comunis agglutinin-I and (c, d) peanut agglutinin (PNA), visualized by avidin-biotin-peroxidase complex and counterstained with methyl green. The sections in (c) and (d) were treated with neuraminidase before labelling with the PNA. Note that the lectin in (a) binds mainly to the inner region of the zona pellucida, whereas in (b) it binds to the outer zona pellucida region. Neuraminidase treatment results in PNA binding to capillary endothelium and intense labelling of the follicular fluid (d). Bars represent $50 \mu \mathrm{m}$.

were found in the inner zona pellucida region. In some instances, for example PNA and RCA-I in rats and SBA in mice, the lectin binding sites were restricted to both the outer and inner regions of the zona pellucida, but were diluted or absent in the central zone.

To determine whether sialyl residues were present in the zona pellucida, we examined binding of PNA after treatment of the deparaffinized sections with neuraminidase. In all ovaries studied, this treatment resulted in extensive exposure of PNA receptor sites in the membranes of some ovarian cells, including most of the oocytes, blood vessel endothelium and granulosa cells (Fig. 2c, d). However, in the zonae pellucidae of the same animals, this procedure did not result in exposure of new or additional binding sites for PNA.

In hamsters, some of the lectins that reacted positively with the zona pellucida, for example GS-I and DBA, exhibited strong positive binding to round, oval or irregular structures located in the stroma outside clearly defined follicles or surrounded by few rows of cells resembling granulosa cells (Fig. 3).

Independent of the lectin-binding capacity of the zona pellucida, the granulosa cells in all species exhibited a similar lectin-binding pattern, expressed as intensive binding of WGA and, to a lesser extent, Con A, LCA and RCA-I (Table 2). PNA bound intensively to the granulosa cells only after treatment with neuraminidase (Fig. 2d). In most instances, the lectin binding in the granulosa cells was restricted mainly to the cell membrane. Positive reactivity to some lectins was also observed in the follicular fluid of all ovaries studied. The lectin-binding pattern of the follicular fluid was generally similar in all species studied and resembled that of the granulosa cells, that is, exhibiting binding of WGA, Con A, 


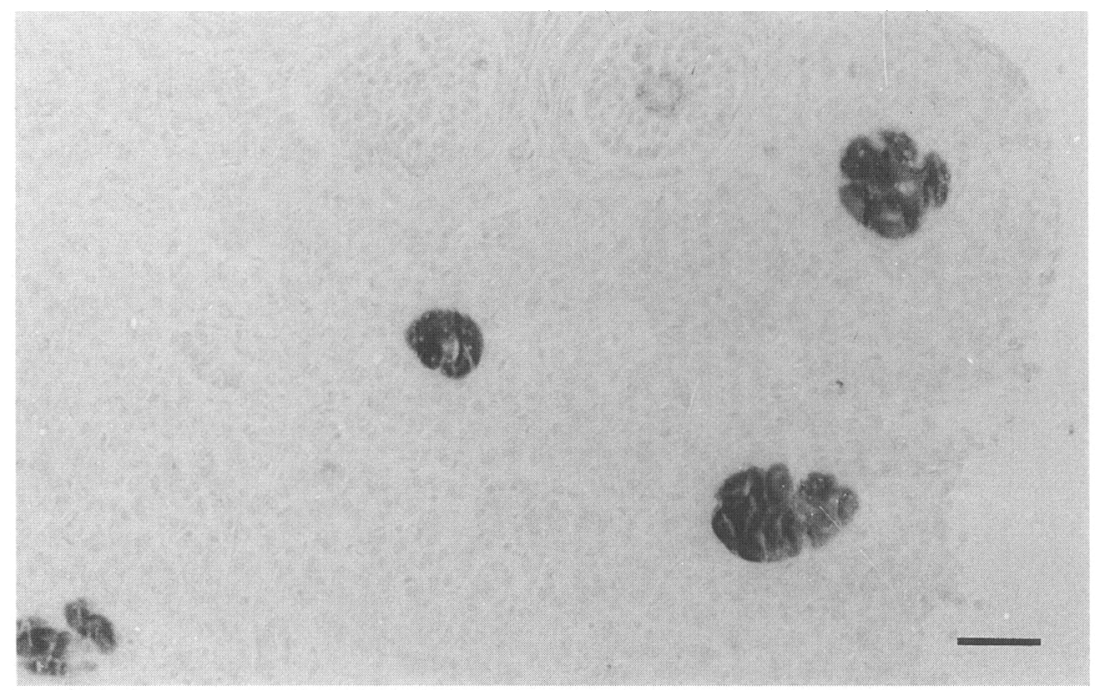

Fig. 3. Photomicrograph of deparaffinized section of hamster ovary, labelled with biotinylated peanut agglutinin (PNA). Intense PNA binding is seen in irregular bodies within the ovarian stroma, probably representing remnants of zona pellucida material of atretic oocytes. Bar represents $50 \mu \mathrm{m}$.

LCA and RCA-I (Table 2). Intensive binding of PNA to the follicular fluid was obtained only after neuraminidase treatment (Fig. 2d).

Incubation with avidin-biotin-peroxidase complex alone, serving as a nonspecific control, did not result in any reaction. In all binding experiments, when lectins were applied in the presence of the appropriate competing sugar (Table I), no binding was observed.

\section{Discussion}

The study reported here demonstrates that the zonae pellucidae of follicular oocytes of different mammalian species exhibit different lectin-binding patterns. Since each lectin binds to specific carbohydrate residues (Lis and Sharon, 1986), the species-specific lectin binding patterns demonstrated in the present study reflect characteristic differences in the content and distribution of specific sugar moieties that are expressed in the zona pellucida. However, lack of lectin binding does not necessarily indicate an absence of the corresponding sugar residue. A lectin receptor site could be undetectable owing to masking by other carbohydrates, or unavailable to the lectin in the histochemical procedure used. Thus, for example, the previously reported presence of fucosyl residues in the mammalian zona pellucida (Shalgi et al., 1986) could not be confirmed in the present study by UEA-I binding. This study demonstrates clearly that the zona pellucida of the follicular oocytes in the species studied are characterized by a higher content of carbohydrate residues, compared with the oocyte itself and the surrounding granulosa cells.

It is interesting that the zonae pellucidae of the different species studied can be characterized by a unique lectin binding pattern that differs at least by the affinity to one lectin. In contrast, the granulosa cells and follicular fluid of all species examined exhibited an identical lectin-binding pattern. The differences in lectin binding patterns of the zona pellucida are more pronounced in evolutionarily distantly related species (for example murine versus canine, feline and suinine) than in closely related species (for example mouse, rat and hamster) which exhibit high similarity in their lectin-binding patterns.

Some of the lectins used, such as LCA, RCA-I and WGA, bound to the zona pellucida of almost all species studied, indicating that some sugar moieties, such as mannose, $\beta$-galactose and $\mathrm{N}$-acetylgucosamine, are commonly present in most mammalian zonae pellucidae. In contrast, some lectins bound to the zona pellucida of only a few or even one of the species studied, probably representing species-specific zona pellucida oligosaccharides. The zonae pellucidae that were most reactive to lectin binding were those of rodents, and to a lesser extent, rabbits. They all share similar binding of S-WGA and PNA, indicating that sugar residues such as $N$-acetylglucosamine and the disaccharide $\beta$-galactose-D- $N$ acetylgalactosamine ( $\beta \mathrm{Gal}-\mathrm{D}-\mathrm{GaINAc})$ are common in rodent zona pellucida. The differences among the rodents were mainly expressed in the binding of GS-I, SBA and DBA. All three lectins mentioned above bound to the mouse zona pellucida, whereas only the GS-I and SBA bound to rat and only SBA to the hamster zona pellucida. Indirect immunofluorescence assays have shown crossreactivity between zona pellucida antigens of phylogenetically close species such as mice and hamsters (Gwatkin, 1977).

The minor differences in carbohydrate expression that exist even between the different rodents may play a primary role in defining the species-specific nature of gamete interaction and in preventing interspecies fertilization even between close species.

In the species studied, except the rabbit, lectin binding to the zona pellucida was relatively poor, compared with that of rodents. Maresh and Dunbar (1987) demonstrated that the zona pellucida proteins of pigs, dogs and cats are antigenically close, whereas those of rabbits are less closely related and rat 
zona pellucida proteins have very little similarity to them. Our results support these observations, demonstrating that the lectin-binding pattern of the rabbit zona pellucida resembles that of the rodents, whereas those of the pig, dog and cat, whose zonae pellucidae carbohydrate patterns resemble each other, exhibit considerable differences from those of the rodents.

Our results also demonstrate that the distribution of most lectin receptors throughout the depth of the zona pellucida is uneven. Independent of the animal species, some of the lectins, including Con A, S-WGA, PNA and RCA-I, bound mainly to the outer region of the zona pellucida, facing the cumulus cells. Some other lectins, including GS-I and DBA in mice, bound only to the inner regions of the zona pellucida, whereas in a few cases (for example WGA), there was binding in both the outer and inner regions. Uneven distribution of lectin receptors in the zona pellucida was previously demonstrated in follicular oocytes of rats (Shalgi et al., 1991). Segregation of the zona pellucida into a number of morphologically distinct layers was also demonstrated in hamsters (Phillips and Shalgi, 1980; Ahuja and Bolwell, 1983) and mice (Kaufman et al., 1989). The important conclusion drawn from our present observations is that specific sugar moieties (i.e. $\beta$-galactose and $\alpha$-galactose in mice) may be differently segregated throughout the same zona pellucida. Assuming that the sugar moieties represent specific zona pellucida glycoproteins, we suggest that different layers of the zona pellucida are characterized by variable content or distribution of its glycoproteins.

This work was supported by grant no. 91-00096 from the United States-Israel Binational Science Foundation (BSF) and by the Basic Research Foundation of the Tel Aviv University. The authors thank L. Ben-Dor and P. Alterman for their technical assistance.

\section{References}

Ahuja KK and Bolwell GP (1983) Probable asymmetry in the organization of components of the hamster zona pellucida joumal of Reproduction and Fertility 69 49-55

Alroy J, Ucci A and Pereira MEA (1984) Lectins: histochemical probes for specific carbohydrate residues. In Advances in Immunochemistry pp 67-88 Ed. RA DeLellis, Mason Inc., New York

Bleil JA and Wassarman PM (1988) Galactose at the nonreducing terminus of the O-linked oligosaccharides of the mouse egg zona pellucida glycoprotein ZP3 is essential to the glycoprotein's sperm receptor activity Proceedings of the National Academy of Sciences USA 85 6778-6782

Dunbar BS and Raynor BD (1980) Characterization of porcine zona pellucida antigens Biology of Reproduction 22 941-954
Florman HM and Wassarman PM (1985) O-linked oligosaccharides of the mouse egg ZP3 accounts for its sperm receptor activity Cell 41 313-324

Goldstein IJ, Hughes RC, Mousigny M, Osawa T and Sharon N (1980) What should be called a lectin? Nature $\mathbf{2 8 6} 66$

Gwatkin RBL (1977) Fertilization Mechanisms in Man and Mammals. Plenum Press, New York

Haung TTF, Ohzu E and Yanagimachi R (1982) Evidence suggesting that $\mathrm{L}$-fucose is part of the recognition signal for sperm zona pellucida attachment in mammals Gamete Research 5 355-361

Kaufman MH, Fowler RE, Barratt E and McDougall RD (1989) Ultrastructural and biochemical changes in the murine zona pellucida during the final stages of oocyte maturation prior to ovulation Gamete Research 24 35-48

Lis H and Sharon N (1986) Lectins as molecules and as tools Annual Review of Biochemistry 55 35-67

Macek MD and Shur BD (1988) Protein-carbohydrate complementarity in mammalian gamete recognition Gamete Research 20 93-109

Maresh GA and Dunbur BS (1987) Antigenic comparison of five species of mammalian zonae pellucidae Joumal of Experimental Zoology 244 299-307

Miller DJ and Ax RL (1990) Carbohydrates and fertilization in animals Molecular Reproduction and Development 26 184-198

Moller CC, Bleil JD, Kinlock RA and Wassarman PM (1990) Structural and functional relationship between mouse and hamster zona pellucida glycoproteins Developmental Biology 137 276-286

Mori K, Daitoh T, Irahara M and Aono T (1989) Significance of D-mannose as a sperm receptor site in the zona pellucida in human fertilization American Journal of Obstetrics and Gynecology 161 207-211

Nicolson GL, Yanagimachi R and Yanagimachi H (1975) Ultrastructural localization of lectin-binding sites on the zona pellucida and plasma membranes of mammalian eggs Journal of Cell Biology 66 263-274

Oikawa T, Yanagimachi R and Nicolson GL (1973) Wheat germ agglutinin blocks mammalian fertilization Nature 241 256-259

Phillips DM and Shalgi R (1980) Surface properties of the zona pellucida Experimental Zoology 213 I-8

Shabanovitz RB and O'Rand MG (1988) Characterization of the human zona pellucida from fertilized and unfertilized eggs Journal of Reproduction and Fertility 82 151-161

Shalgi R, Matityahu A and Nebel L (1986) The role of carbohydrates in sperm-egg interaction in rats Biology of Reproduction 34 446-452

Shalgi R, Maymon R, Bar-Shira (Maymon) B, Amihai D and Skutelsky E (1991) Distribution of lectin receptor sites in the zona pellucida of follicular and ovulated oocytes Molecular Reproduction and Development 29 365-372

Shimizu S, Ito M and Dean J (1982) Glycoproteins of mouse zona pellucida: analysis of their reactivity to lectin Biochemistry and Biophysics Research Communication 109 449-454

Spicer SS and Schulte BA (1992) Diversity of cell glycoconjugates shown histochemically: a perspective Journal of Histochemistry and Cytochemistry $\mathbf{4 0}$ I-38

Wassarman PM (1988) Zona pellucida glycoproteins Annual Review of Biochemistry 57 415-442

Wu TC, Lee MC, Wan YJ and Damjanov I (1984) Lectin binding sites of the mouse ovary, intraovarian and ovulated ova Histochemistry 80 527-533

Yanagimachi R (1988) Mammalian fertilization The Physiology of Reproduction pp 135-185 Eds E Knobil, JD Neil, LL Ewing, GS Greenwald, C Market and W Pfaff. Raven Press, New York 